\title{
The Issues of Roadside Litter: A Review Paper
}

\author{
Kasra Karimi, Ardeshir Faghri \\ Department of Civil and Environmental Engineering, University of Delaware, Newark, USA \\ Email: faghri@udel.edu
}

How to cite this paper: Karimi, K., \& Faghri, A. (2021). The Issues of Roadside Litter: A Review Paper. Current Urban Studies, 9, 779-803.

https://doi.org/10.4236/cus.2021.94046

Received: November 2, 2021

Accepted: December 12, 2021

Published: December 15, 2021

Copyright (c) 2021 by author(s) and Scientific Research Publishing Inc. This work is licensed under the Creative Commons Attribution International License (CC BY 4.0).

http://creativecommons.org/licenses/by/4.0/

\begin{abstract}
Roadside litter is a growing problem in many countries around the world including the United States. More people, more vehicles, and more products are factors that have aggravated the problem over the years. Additionally, the global pandemic due to COVID-19 has drastically increased the amount of litter, particularly for certain types of products such as Personal Protective Equipment (PPE) and single-use packaging items. The detriment of roadside litter is not limited to aesthetic problems. From a general perspective, litter is associated with social, economic, and environmental issues. Further, from a transportation standpoint, some types of roadside litter can interrupt the flow of traffic, cause delays, or even pose safety hazards to road users. This study conducts a review of the existing literature to depict a holistic perspective of the cause and extent of the problem in the U.S., as well as discusses the current litter abatement strategies. This paper looks at the behavioral aspect of littering, the characteristics of litter, and different prevention and removal strategies.
\end{abstract}

\section{Keywords}

Litter, Roadside, Road, Trash, Environmental

\section{Introduction}

The term litter generally refers to any misplaced solid waste (Forbes, 2009). Fast food packages, drink containers, plastic bags, shredded tires, and many other pieces of litter are some of the common items sitting along the roadways. Illegal dumping is another form of misplaced solid waste that is distinguished from litter by most sources, albeit some people have treated the two categories as one (Nelson, 2001). Environmental Protection Agency (EPA) (1998) defines illegal dumping (also known as "fly dumping", "open dumping", and "midnight dumping") as "primarily non-hazardous materials that are dumped to avoid either 
disposal fees or the time and effort required for proper disposal". Based on these definitions, the intention of the person at fault seems to determine whether the misplaced waste is considered litter or illegal dumping. However, there is usually a significant difference between the two groups in terms of the material type. Illegal dumping usually consists of larger items such as construction debris, furniture, and mattresses, while litter mostly consists of smaller items thrown out by vehicle occupants and pedestrians. From a transportation standpoint, litter and illegal dumping can both cause safety and operational issues as well as make our roads visually unpleasant. Furthermore, they are associated with various, social, economic, and environmental issues.

Any external object on the road can pose safety hazards and cause operational issues for road users. Larger items, in particular, can interrupt the traffic flow and cause delays. More importantly, such situation can directly or indirectly lead to a collision. Debris-related crashes are reported to constitute $0.1 \%$ to $0.5 \%$ of all crashes (Forbes, 2004). Furthermore, every time there is a litter removal effort, both the clean-up crew and other road users can be exposed to the risk of collision. Leftover foods alongside the roads can also attract animals and increase the chance of wildlife-vehicle collisions (Forbes, 2009).

The environmental impact of the roadside litter can go far beyond the boundaries of the roadway network. Toxic materials such as the chemical components of cigarette butts can be washed away with rain and contaminate the soil and the groundwater (Novotny, Lum, Smith, Wang, \& Barnes, 2009). Studies have confirmed the impact of the cigarette butt's toxicity on marine and freshwater fish (Slaughter et al., 2011). Light-weight litter items can be blown by the wind or be carried by the rain runoff and end up in streams, rivers, and drains, and even find their way to the ocean (see Figure 1 and Figure 2). Some plastics decompose into microplastics after some time in the ocean, not only polluting the water and harming marine life but also can end up in our food chain (Gregory, 2009; Thiele, Hudson, Russell, Saluveer, \& Sidaoui-Haddad, 2021).

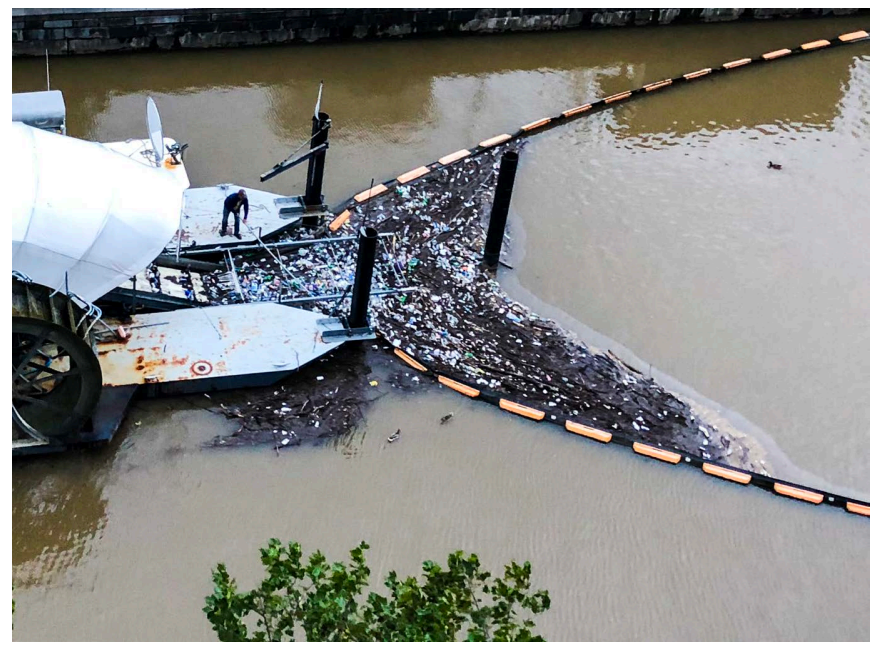

Figure 1. Roadside litter that ended up in a river (Inner Harbor, Baltimore). 


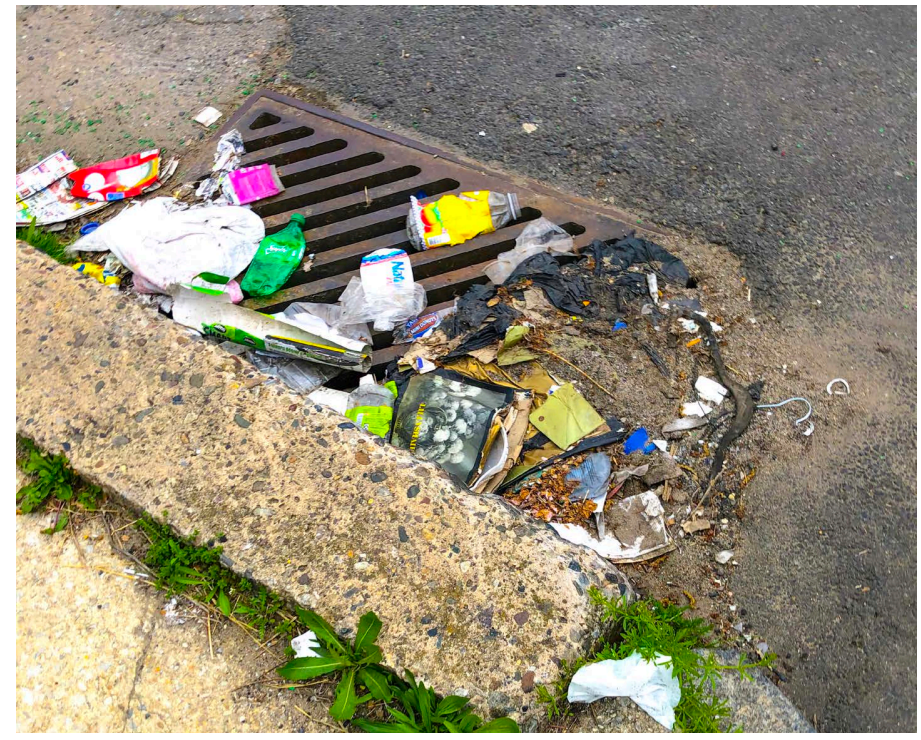

Figure 2. Litter items trapped by a drain grate (Philadelphia).

The environmental impact of plastic litter is particularly concerning due to the significant increase in the human desire to use plastic. In 1950 the world produced only 2 million tons per year. Since then, annual production has increased by nearly 200 times, reaching 381 million tons in 2015 (Ritchie \& Roser, 2018). It is estimated that 8.3 billion tons of plastic have been created over the past 50 years, only $9 \%$ have been recycled, and the rest has gone to landfills or ended up as litter in the environment (Pacific, 2019). It may take weeks to even hundreds of years for different types of litter to be completely decomposed in nature, and many different species can be harmed during the litter's so-called afterlife. An animal being trapped or hurt by a piece of litter is an unfortunate but common scene that is a direct consequence of the litter problem.

Litter is very costly to be removed. Federal and local governments, businesses, volunteer organizations, and individuals in the U.S. spend nearly $\$ 11.5$ billion each year for removing all sorts of litter (Stein, 2009). Such a budget could be spent on more essential needs if this issue could be prevented in the first place. In 2009, State Departments of Transportation (DOTs) were reported to spend about $\$ 430$ to $\$ 505$ for collecting and disposing of litter per centerline mile (Forbes, 2009). Beck (2007a) estimated that local and DOT efforts for litter clean-up cost Georgia nearly $\$ 20$ million each year. Another study in Utah claimed that the annual cost of highway clean-up ranges between $\$ 1.53$ million to $\$ 1.83$ million. Similarly, the Delaware Department of Transportation (DelDOT) spends nearly $\$ 2$ million for litter cleanup annually (State of Delaware News, 2019).

Moreover, there are indirect costs also associated with roadside litter, particularly, in urban environments. A littered area is more likely to experience a decrease in property value. Businesses in such areas are also more prone to face economic losses because of the diminished interest of the visiting public. Nelson 
(2001) also points out a known correlation between the increase of litter in an area and the level of people's sense of well-being and crime.

Concerns about the litter problem in the U.S. have been raised at least since the 50s when the Keep America Beautiful (KAB) organization was established for the premise of litter prevention and beautification (Forbes, 2009). Since then, many organized volunteer, federal, and local efforts have been undertaken to tackle this problem. However, the pace at which contractors and volunteers are picking up litter is much slower than the pace at which people are littering. The growth of the population and the increased number of Vehicle-Miles Traveled (VMT) have potentially increased the exposure rate of litterers on the roads. Further, the consumerism culture has led an average person to consume more products than ever in history which can potentially result in more items being littered. Although fighting the litter problem was already an ongoing struggle in many states, the emergence of the global pandemic due to COVID-19 in 2020 drastically aggravated this existing issue.

The unprecedented emergence of the global pandemic caught the world unprepared in various aspects. Properly disposing of a myriad of Personal Protective Equipment (PPE) and cleaning products such as face masks, latex gloves, and wiping pads was one of them. It was estimated that every month, 129 billion face masks and 65 billion gloves were used globally during the COVID-19 pandemic (Prata, Silva, Walker, Duarte, \& Rocha-Santos, 2020). Additionally, the demand and use of single-use plastic for packaging and other purposes surged drastically during the pandemic (Silva et al., 2021). The increase in production and use of certain products on one hand and people's urge for immediate disposal of those items due to health concerns, on the other hand, led to a situation that such items could be seen on the streets more than ever before. Another major concern raised by COVID-19 was the health of the litter removal crew and volunteers against the disease. Most litter pick-up programs involving inmates and volunteers, and community-based cleanup events were put on hold due to the gathering restrictions (Semuels, 2021).

The issue of litter is a growing problem in the U.S. as well as many other parts of the world. The current efforts do not seem adequate to respond to this rising problem and much more effective measures need to be established. In terms of academic research, the existing studies are very few and disperse compared to the size of the problem and its social, environmental, and economic impact. Further, the issue of litter is a complex multidisciplinary topic and this might be confusing for those who seek to get familiarized with its different aspects. This study strives to acquaint the readers with a general perspective of this issue and provide them with a concise yet comprehensive knowledge on the behavioral aspect of littering, identifying the characteristics of roadside litter, the traffic safety impact of litter, and lastly, different current litter abatement strategies. For this purpose, a literature review is conducted among the academic and non-academic related publications. 


\section{Littering Behavior}

\subsection{Negligent vs. Deliberate Littering}

Littering behavior is usually considered to be either negligent or deliberate. Different studies have also used other terms such as "accidental", "careless", and "intentional". Deliberate littering is defined as throwing, dropping, or discarding material or products in inappropriate locations intentionally (Beck, 2007b). Throwing out trashes from a vehicle and illegal dumping can be examples of this case. Negligent, accidental, or unintentional littering, on the other hand, happens when material or products end up on the road with no direct intention. Vehicle debris from accidents or wear, material that falls from vehicle loads can be examples of this type. This category can also include items that spill from overloaded or tipped trashcans (Beck, 2007b). Determination of whether an item was deliberately littered or negligent can be difficult if the act of littering happened in the past. Beck (2007b) claims that based on the previous observations, some items such as snack wrappers, take-out food packaging, and beverage-related litter usually associate with deliberate littering, while newspapers, fliers, construction debris, and miscellaneous scraps have been usually linked to negligent littering.

Forbes (2009) and Beck (2007b) both question using the term "accidental" since it may imply that the litterer was not at fault, instead suggesting using "negligent" litter since many of this litter type can be prevented by willful acts such as securing cargos. Forbes (2009) claims that the dominant type of littering in the U.S. has shifted from deliberate to negligent which might be as a result of the preventive programs. However, Schultz's (2009) observations of 9757 individuals littering in 10 states revealed that $81 \%$ of littering was notably intentional through acts such as dropping, flick, and fling.

There are multiple factors that can affect negligent littering. The littering behavior of the same group of people might be different in various locations. Studies have unanimously reported that the presence of existing litter is a determining factor in people's decision whether to litter or not. Individuals tend to adjust their behavior based on their perception of the norm of their surrounding environment (Schultz, 2009). The presence of even a few pieces of litter can imply the message that littering is acceptable in this area (Nelson, 2001). The theory of the "Broken Window" suggests that the presence of litter can convey the "no consequences" message in those neighborhoods and even be linked to other crimes (Kelling \& Coles, 1997). Another factor is the presence of receptacles. Schultz (2009) reported that lack of receptacle availability accounts for up to $15 \%$ of the littering. This can be a much more crucial matter in the case of cigarette butt litter.

\subsection{Litterers Profile}

Two important questions regarding the behavioral aspect of littering are "who litters and why". Identifying the profile of litterers can be a helpful step for es- 
tablishing more effective prevention and control programs (Nelson, 2001). Often, different preventive slogans and strategies need to be chosen to target different age groups and genders. There are a few surveys that have tried to identify the characteristics of litterers such as gender and age. The early study of Keep America Beautiful (KAB) 1968, revealed that males litter twice as much as females. Adults younger than 35 , also found to be twice more likely to litter than the age group of 35 - 49, and three times than the age group of 50 plus (Forbes, 2009). Other studies have also indicated young males aged 18 - 34 to be the most likely group to litter, particularly regarding intentional flicking (Beck, 2007a; Gershman, Brickner \& Bratton, Inc., 2005; Morris, 2006; Responsive Management, 2006; Stein \& Environmental Resources Planning, 2010). Beck (2007a) also indicated that deliberate littering among teenagers between 11 to 17 is also very high, yet the $18-24$ group has the highest rate.

Littering is considered a social problem caused by the misbehavior of individuals whether it occurs intentionally or accidentally (Schultz, 2009). Surveys in the U.S. have shown that the majority of people are aware of littering as a problem, yet, many of them litter. A survey among smokers showed $74.1 \%$ admitted they have littered cigarette butts (Rath, Rubenstein, Curry, Shank, \& Cartwright, 2012). In a 2006 survey in Georgia, 97\% of the participants agreed that litter hurts the state's environment (Responsive Management, 2006). Findings of five litter behavioral surveys from 1968 to 2006 showed that even though most people know litter is a problem, about 40 - 50 percent of the participants admitted that they have littered in the past (Beck, 2007b). A more recent attitude survey in Pennsylvania (Burns \& McDonnell, 2020) revealed that over 90 percent of the responders believed that litter is a problem in the commonwealth.

Various reasons could be behind the littering behavior, multiple surveys asked the question of "why do people litter?" and the most common responses included carelessness, laziness, lack of trash cans availability, and inadequate enforcement (Beck, 2007b). The KAB claims lack of ownership as one of the main reasons that cause people not to consider themselves responsible for cleaning the public environment. Another contributing factor might be due to the tendency of people to regard litter as having disappeared or been taken care of by someone else.

\section{Characteristics of the Litter}

One of the primary goals of any litter surveys is to assess the amount, type, location, and source of the litter that already exists on the roadsides. This is a key step in establishing preventive and controlling strategies. The amount and type of litter can be affected by many factors such as the classification of the road, traffic volume, urban or rural area. Some of the reviewed studies only surveyed the visible litter, which is referred to the items larger than four inches in size, while some have also counted smaller pieces down to one inch. Lack of a uniform standard metric for reporting collected litter is an obstacle for a side-by-side com- 
parison of the result of different studies and different preventive and controlling strategies (Forbes, 2009; Spacek, 2008). For instance, different studies have used a variety of units for reporting the amount of collected litter including weight, volume, number, truckloads, area, and the number of trash bags (Forbes, 2009). In the following, the key characteristics of the litter are discussed based on a number of selected surveys and studies.

\subsection{Composition}

Several surveys related to the composition of litter in the national and states levels were reviewed for this section and a few of the most comprehensive ones were chosen and presented in chronological order.

\subsubsection{Georgia (Beck, 2007a)}

Beck (2007a) conducted a visual litter survey in the state of Georgia at 96 sites and quantified the composition of litter. This report presented the result in twenty-two groups with respect to being either deliberate (ten groups) or negligent (twelve groups). Figure 3 shows the top-ten most frequent categories found by this study. These categories comprise nearly $90 \%$ of all litter. Miscellaneous plastic scraps and miscellaneous paper scraps comprised nearly $41 \%$ of the items found. Snack food packaging, vehicle debris, and packaging had the highest rate of negligent litter. Vehicle packaging was defined as the wrappers and discarded materials from automobile parts and servicing materials that are purchased at car parts shops and other stores. Cigarette butts did not meet the size threshold in this study yet they were counted separately in a smaller portion of each survey site. Approximately 42,912 cigarette butts were found which was eight times more than the total amount of other litter found on roadway edges.

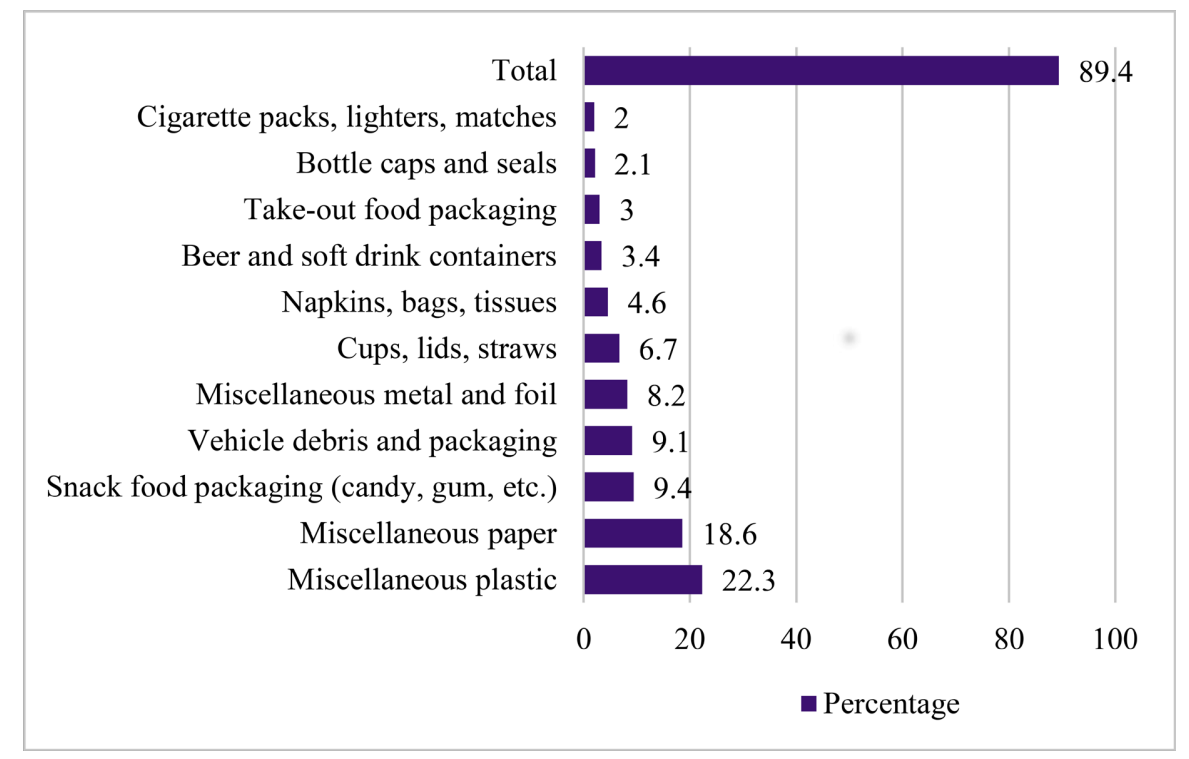

Figure 3. Top-ten most frequent categories of litter in Georgia (Beck, 2007a). 


\subsubsection{KAB Literature Review (Beck, 2007b)}

Beck (2007b) conducted a literature review for KAB and analyzed the result from nine litter surveys (including the 2006 Georgia survey mentioned above) that utilized an Institute for Applied Research (IAR) methodology, to attain the composition of litter for all nine states. This method uses stratified random sampling techniques to visually count the number of items one inch or greater in size. The author casts doubt on whether cigarette butts were counted in those surveys or not. The result is presented in Figure 4 which shows the composition of visible litter in eleven litter categories. Snack wrappers and food packaging comprised the largest percent of littered items by almost 13\%. Miscellaneous paper and plastic each formed nearly $12 \%$ of all litter. On average these eleven categories of products comprise just nearly $88 \%$ of the total visible litter.

\subsubsection{KAB National Study (Stein, 2009)}

The 2009 nationwide study by KAB has gathered data from 240 locations from 45 states (Alaska, Delaware, Hawaii, New Hampshire, and Rhode Island were excluded). The locations were chosen randomly from both rural and urban areas and different types of roadways. This study estimated there are 51.2 billion pieces of litter on the roadways in the United States, $91 \%$ of which being less than four inches in size. The pie chart in Figure 5 shows the composition of the litter on the U.S. roadways based on the number of items. Tobacco products including cigarette butts, cigars, chewing tobacco, and packaging are the most common items forming about $38 \%$ of all litter. Paper and plastic are in second and third place with near $20 \%$ each.

$\mathrm{KAB}$ also provided the list of the top ten litter items by number. Out of sixty-one categories of litter defined by this study, those top ten items account for near $80 \%$ of the total number. The cigarette butt with $36 \%$ was found to be the most common item that can be found along the roadways followed by papers (14.2\%) and plastic litter (5.7\%). KAB has also identified the most frequent types of litter based on a more specific product classification which are presented in Figure 6. Cigarette butts and other types of tobacco products comprised $38 \%$ of

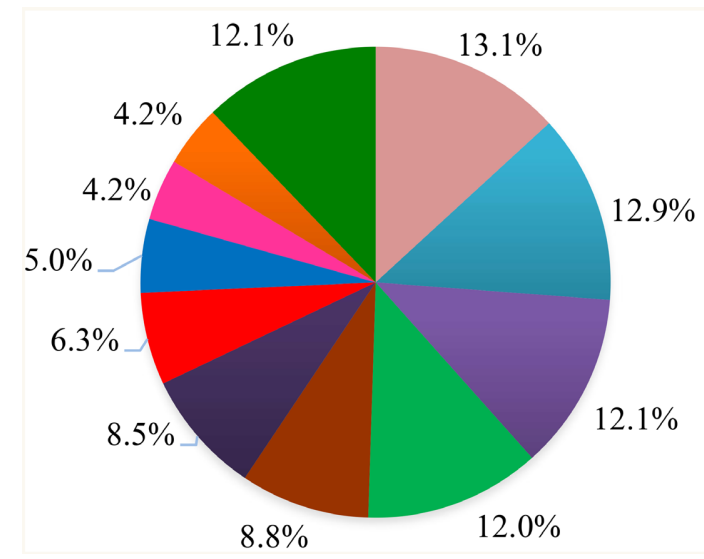

$\square$ Takeout Food Packaging - Snack Wrappers

Misc. Paper

Misc. Plastic

- Vehicle Debris

- Beverage Containers - Napkins, Bags, Tissues - Misc. Metal \& Glass

- Other Beverage Related - Construction Debris

- Others

Figure 4. Composition of the litter in ten states (Beck, 2007b). 


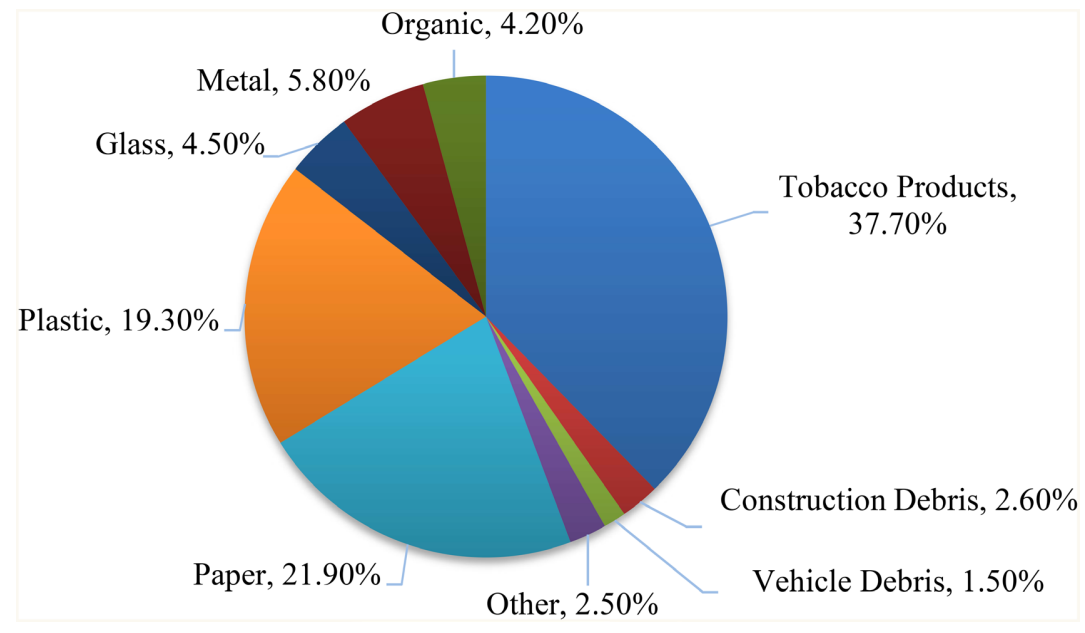

Figure 5. The material composition of the litter on U.S. roadways (Stein, 2009).

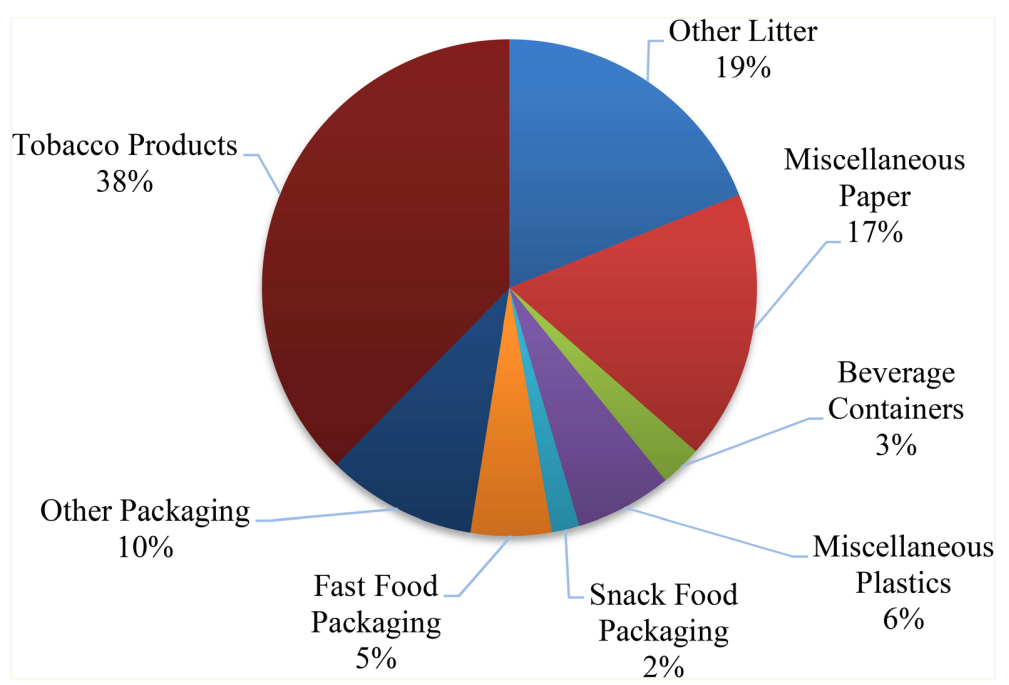

Figure 6. Litter type of interest (Stein, 2009).

the total litter. Snack food packaging, fast food packaging, and other packaging types plus container bottles accounted for about $20 \%$ of all items. Product packaging comprised $41 \%$ of the large litters (4 inches and larger). The study claims that nearly two-thirds of the material used in the productions of these packaging is plastic. Among beverage containers, beer (30.5\%), soft drinks (24.6\%), and water bottles (5.9\%) had the largest share of the recognizable containers.

A comparison between the result of this study and the previous KAB national study in 1969 showed that the total amount of visible litter has decreased by approximately $61 \%$ over the last 40 years. However, certain types of litter have increased drastically. The percentage of plastic, in particular, has increased extremely by $165 \%$ on rural interstates and primary roads which is a reflection of the surge in plastic production and consumption over this period.

\subsubsection{Anacostia (Environmental Resources Planning, 2015)}

A litter survey was conducted in 2015 in the Anacostia Watershed, which en- 
compassed certain portions of the District of Columbia (DC) as well as Montgomery and Prince George's counties in Maryland. This document reported the components of litter in two separate groups of large (4 inches plus) and small (4 inches minus) litter from 84 roadway sites. The top three large items in the order of counts were sweet snack wrappers (7.9\%), paper fast food napkins (6.9\%), and miscellaneous paper (5.9\%). For small litter, the top three items were glass (28.7\%), cigarette butts (23.8\%), and paper scraps (15.0\%). Plastic and paper form $73 \%$ of the all large litter group and for the small litter glass and tobacco with $57 \%$ are the two dominant materials.

\subsubsection{New Jersey (Stein, 2018)}

This litter survey (Stein, 2018) was conducted in 2017 on 94 roadway sites throughout the state of New Jersey to identify the amount and composition of the litter. The methodology used in this survey was set to account for items one inch or larger so the result would be comparable to a former survey which was conducted in 2004 in this state. The result showed the top five common categories of the litter were vehicle/construction-related items, paper, beverage containers, cups/lids/straws, and candy/snack packaging. Moreover, the top five items of litter most frequently found in New Jersey litter during this survey were tire scrap, paper, shrink wrap, sweet snack packaging, and plastic water bottles.

\subsubsection{Delaware (DSM Environmental \& MSW Consultants, 2018)}

Keep Delaware Beautiful (KDB) conducted a litter survey on 60 road segments. The methodology used for this survey was based on the KAB national study (Stein, 2009). This study also reports the litter composition in two groups of large (greater than 4-inch) and small litter (smaller than 4-inch) which are represented in Figure 7. It can be seen that for large items, plastic and paper together accounted for $67 \%$ of all litter, and for small litter, tobacco, plastic, and paper were the major categories with accounting for $88 \%$ of this group. The dominancy of tobacco (mainly cigarette butts) among small litter complies with other studies. The share of plastic products is significant in both categories.

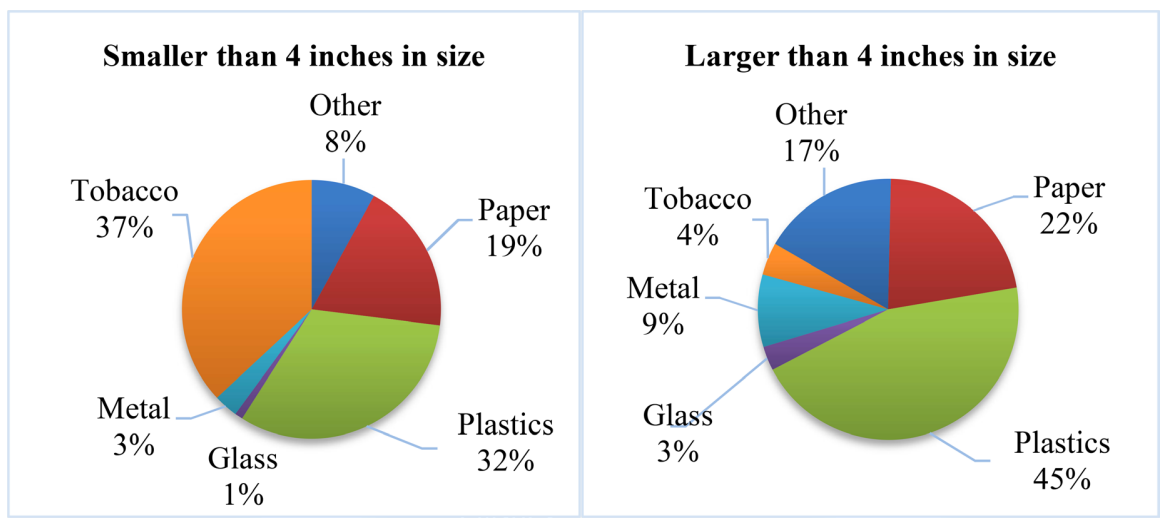

Figure 7. Composition of litter by material in Delaware (DSM Environmental \& MSW Consultants, 2018). 


\subsubsection{Pennsylvania (Burns \& McDonnell, 2020)}

A recent litter survey was conducted in 2018-2019 in Pennsylvania over 180 sites by (Burns \& McDonnell, 2020). The study estimates over half a billion pieces of litter to exist on Pennsylvania roadways. This report breaks down the litter into six groups: paper, plastic, glass, metal, organic, and others, each subdivided into more specific categories ( 85 in total). With 186.2 million pieces, cigarette butt was the most frequent item which formed 37.1 percent of the total litter. The composition of the litter is shown in Figure 8 for both larger and smaller groups. Plastic had the next highest share with $30.4 \%$. About $85 \%$ of the litter in Pennsylvania was 4 -inches or smaller in size. Those bigger than 4 inches (visible litter) comprised $15.5 \%$ of the litter by count. Plastic composed the majority ( 45.0 percent) of larger litter while cigarette butts composed the majority (43.3 percent) of smaller litter. Similar to the Delaware survey, the percentage of plastic in both groups seem be significantly higher compared to older surveys, including the KAB national study.

\subsection{Source}

Although pedestrian and motorists are known to be the major sources of litter on the roads, there are not the only ones. Stein (2009) identifies seven major sources of litter as follow:

1) Pedestrians or cyclists;

2) Motorists;

3) Business dumpsters that are improperly covered (see Figure 9);

4) Vehicles with uncovered loads (see Figure 10);

5) Loading docks and commercial or recreational marinas with inadequate waste receptacles;

6) Construction and demolition sites without tarps and receptacles to contain debris and waste;

7) Household trash scattered before or during collection.

Forbes (2004) expands the source (d) to vehicle-related debris which also includes automotive parts and tire scraps that have been fallen on the roads due to
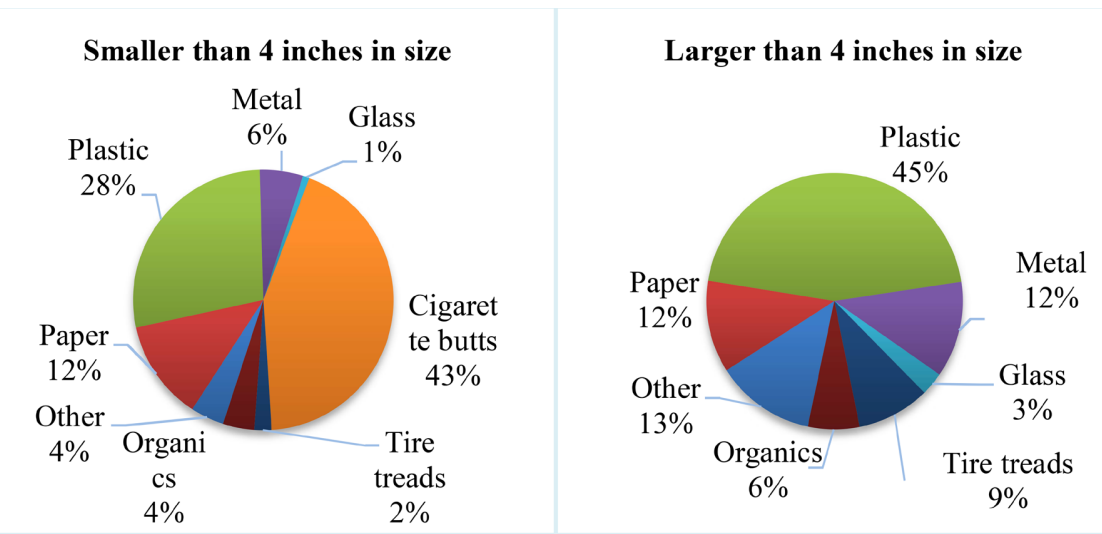

Figure 8. Composition of litter by material in Pennsylvania (Burns \& McDonnell, 2020). 


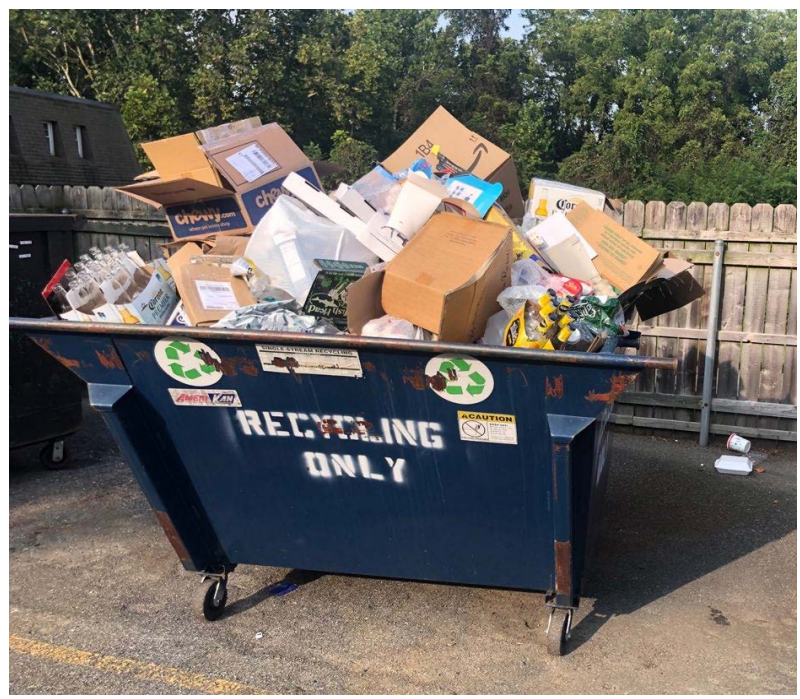

Figure 9. An example of an improperly covered receptacle.

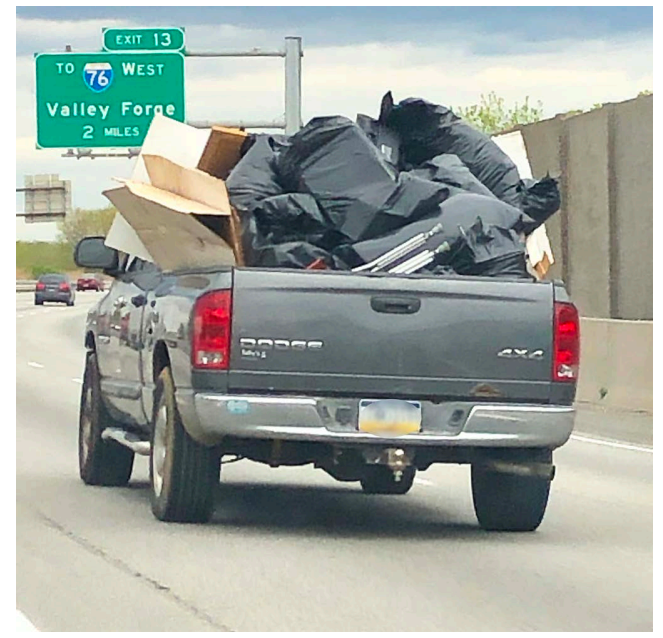

Figure 10. An example of an unsecured load on a pickup truck on an Interstate.

collisions or wear and tear. Based on the definition of negligent and deliberate littering given in Section 2.1, the litter originating from sources (c) to (g) is associated with negligent litter, while motorists and pedestrians can be associated with either group.

The $2009 \mathrm{KAB}$ national study represents the likely sources of litter for individual items as represented in Figure 11. Unsurprisingly, near $76 \%$ of the total roadside litter directly comes from motorists and pedestrians. Moreover, KAB presents the source of litter by road classifications. The result indicated that the contribution of each source can vary for different road types. On city roads, pedestrians are the main contributors to the littering problems, while in all other road types motorists are the leading source. The share of unsecured loads was found to be the highest on the state roads and for vehicle debris litter, national roads had a greater portion. The Pennsylvania study also found improperly secured loads and vehicle debris had the highest rate on the interstates roadways 


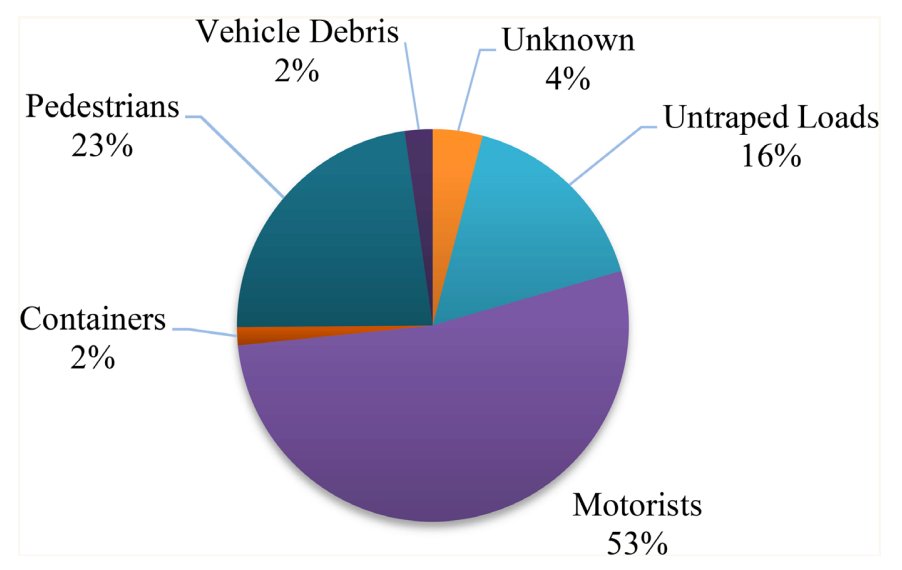

Figure 11. Source of litter on the U.S. roadway, recreated from (Stein, 2009).

\section{(Burns \& McDonnell, 2020).}

Forbes (2009) claims that $97 \%$ of litter comes from four sources: pedestrians $(42 \%)$, vehicle occupants (20\%), uncovered or unsecured loads on trucks $(21 \%)$, and open vehicle beds where items had been improperly stowed (14\%). Motorists and pedestrians have also been identified by other studies to be leading sources of litter for both small and large items.

\subsection{Road Type and Location}

The type of roadway and the area it is passing through are two factors that can significantly affect the roadside litter rate. In the previous section, we also discussed how the source of litter can vary with the type of road. There are a number of factors that can affect the rate of litter in different locations and road types. Road traffic, road length, population, the distance of businesses and shops to the road, and frequency of them (specifically fast-food restaurants and convenience stores) is some of the major factors (Conroy-Ben \& Christensen, 2013).

\subsubsection{Georgia (Beck, 2007a)}

The Georgia survey (Beck, 2007a) reports the rate of visible litter for different road types and location zones. Figure 12 shows those findings which indicate urban freeways have the highest rate of visible litter items per mile followed by rural freeway/toll roads. Residential streets, rural local roads, and streets in front of public facilities with close to 1000 visible litter items per mile were the least littered roads (Beck, 2007a).

A specific index was defined by this study to measure the visual impact of the litter which indicates the locations where people are more likely to be exposed to litter. The exposure rate was calculated based on the amount of litter and the traffic volume of the road type. The result which is shown in Figure 13 indicates that urban freeways and residential streets have the highest rates of exposure with nearly $27 \%$ each. Despite the low rate of litter per mile, the high volume of the pedestrian and motorist increases the exposure rate. 


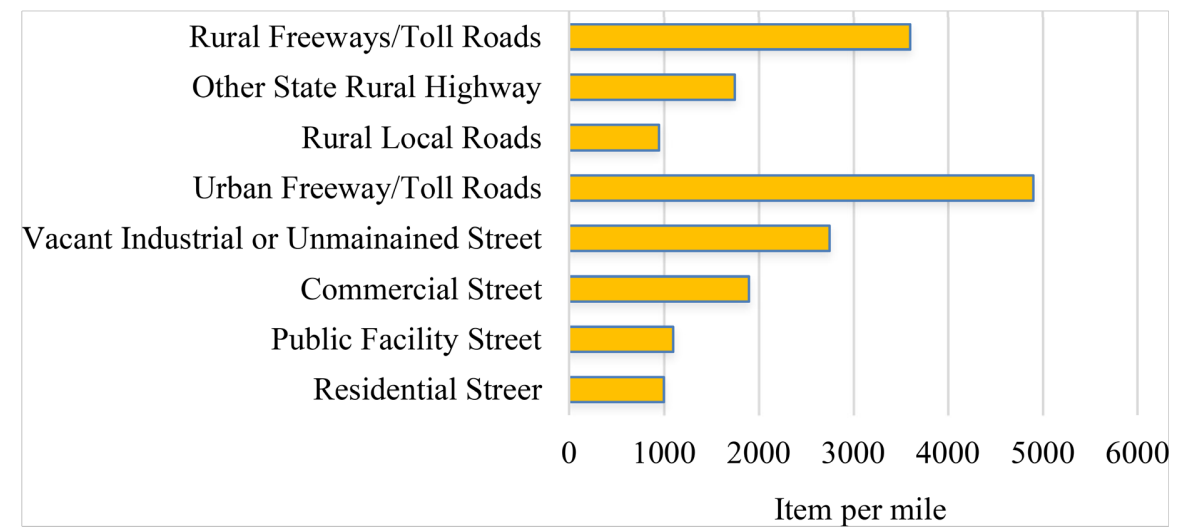

Figure 12. Source average litter rate by location (Beck, 2007a).

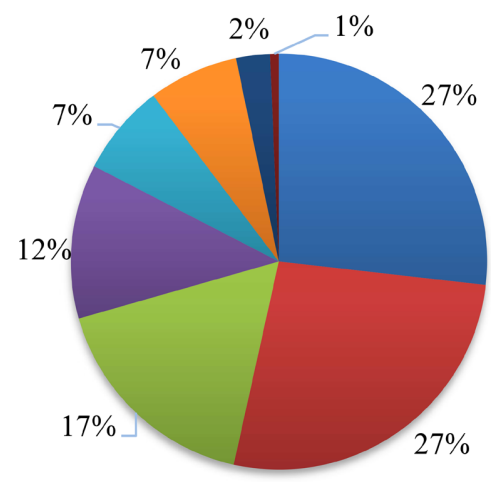

- Residential Street

- Urban Freeway/Toll Roads

Public Facility Street

- Rural Local Roads

- Rural Freeways/Toll Roads

- Vacant Industrial or

Unmainained Street

- Commercial Street

- Other State Rural Highway

Figure 13. Exposure to litter by location (Beck, 2007a).

Overall, in Georgia, urban and rural freeways were found to be the most littered of all roadway types mainly because of their high traffic levels. A high level of negligent litter was also observed on these two roadway types which indicated the impact of unsecured truckloads (Beck, 2007a). Additionally, the higher speed of the vehicle on those roads can be a contributing factor that causes improperly covered materials to fly out of the vehicles. Mowing is also introduced as a factor that can affect the rate of litter for different locations. This study claims that mowed areas were generally more littered than non-mowed areas.

\subsubsection{KAB National Study (Stein, 2009)}

The KAB 2009 national study analyzed the roadway litter result based on the area classification and type of the roadway and determined both the average number of items per mile of the roadway and the total litter. Figure 14 shows litter by area classification and demonstrates that the density of the litter is higher in a mile of a road in urban areas. However, the overall number of litter items on rural roads is more than twice as on urban roads, due to a higher number of miles. Figure 15 displays the number of litter items per mile of the road and the total litter based on the classification of the road. As it can be anticipated, when the traffic volume increases the density of litter on the roadway increases as well, but in terms of total litter over the country, there is more litter on the 


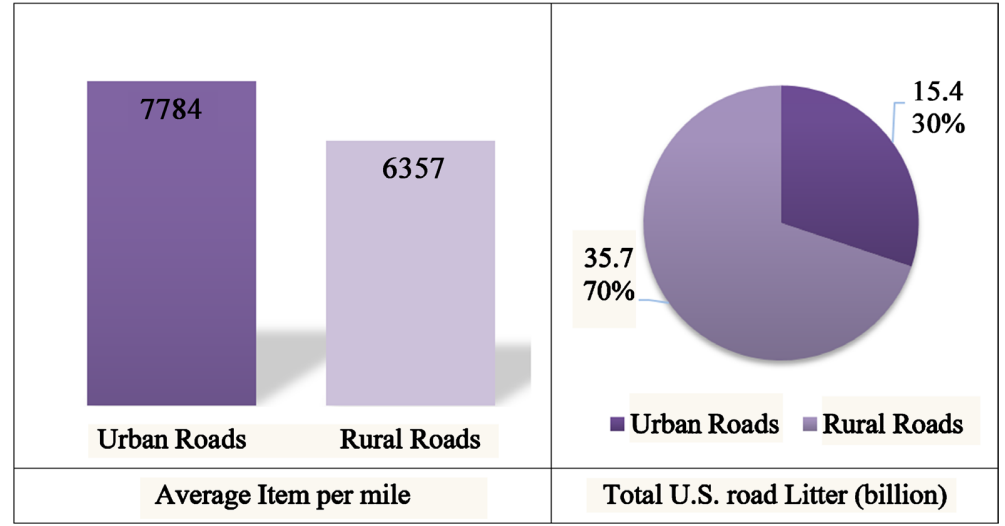

Figure 14. Litter in the U.S. by urban and rural types (Stein, 2009).

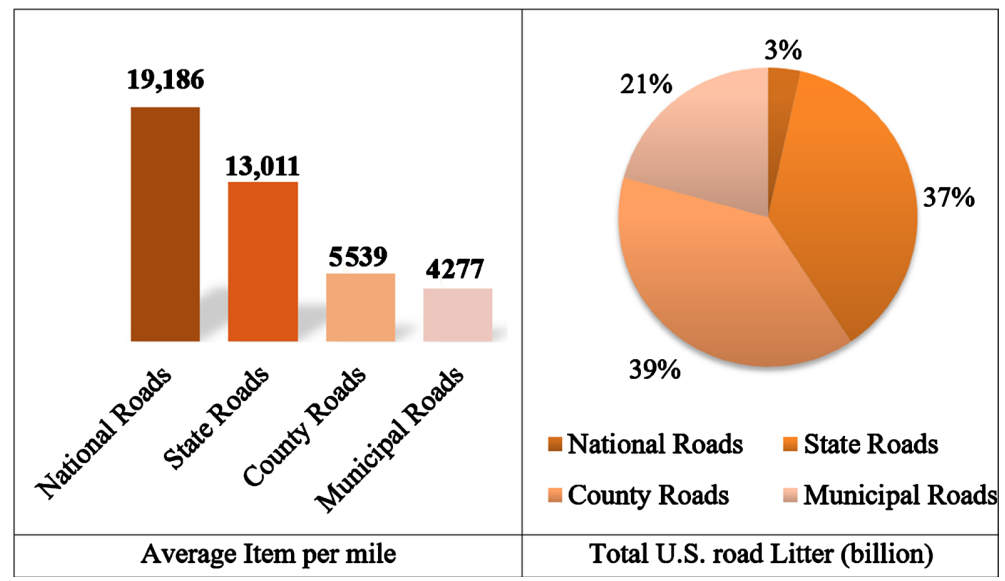

Figure 15. Litter in the U.S. by roadway type (Stein, 2009).

county roads and state roads because of their higher number of miles.

\section{Traffic Safety Impacts}

Roadside litter can pose safety hazards on the roads for pedestrians, bicyclists (and other means of micromobility), and motor vehicle. The most problematic types of litter that can lead to major collisions with injuries and even fatalities are fallen cargo, wheel separations, and other highway debris. However, even small objects, if segregated from the vehicle and discharged on the road can directly damage other motorists or causing a crash due to other vehicles maneuver for avoidance. Forbes (2004) defines road debris as any substances, materials, or objects that are foreign to the normal roadway environment. Usually, such materials fall into the definition of litter or illegal dumping and can be originated from vehicles or other sources.

Forbes (2004) investigates the frequency and severity of the crashes caused by Vehicle-Related Road Debris (VRRD) in North America and estimated that VRRD can contribute to over 25,000 crashes per year, claiming 81 to 90 lives. A study in Michigan states debris, oil, and gravel on the road accounted for an average of $4.4 \%$ of serious motorcycle crashes (Spink, 2006). The National High- 
way Traffic Safety Administration (NHTSA) reported of 51,000 crashes involving collisions with non-fixed objects in 2010 which resulted in 10,000 injuries and 440 fatalities (GAO, 2012). Although the exact type of the objects was not specified, a significant portion of them are expected to originate from vehicle-related debris, and illegal dumping. In Utah, between 650 to 800 litter-related crashes were reported in five years, among them were five fatal ones (Conroy-Ben \& Christensen, 2013). Although litter-related crashes form only a fraction of all road crashes, for moving towards the "Road to Zero" goal, preventive measures must be established to mitigate this risk.

VRRD can be originated from all types of vehicles, whether as debris of an accident or vehicle parts and equipment that break loose and came off due to wear and tear. Blown tires, tire treads, drive-shafts, fenders, bumpers, hoods, leaf springs, and brake parts can all lead to serious crashes. Tire scrap makes a big portion of vehicle debris left on the road. Maintenance issues (e.g., under-inflation, overloading, tire mismatching, excessive wear, inadequate inspections, and associated matters leading to increased heat and tire operating temperatures) are the major causes of a tire blowout (Bareket, Blower, \& MacAdam, 2000). The roughness of the road surface can be a major factor in the amount of litter that origins from unsecured loads and smoothing the road can decrease the number of crashes related to lost unsecured loads up to $51 \%$ (1981).

The crashes caused by VRRD or other forms of large litter can happen in various ways, either direct or indirect. Forbes (2004) describes eleven scenarios in which debris can lead to a vehicle collision. The direct collision occurs when a vehicle directly hits the object. The indirect collisions happen when one vehicle tries to avoid hitting the object and either collides with other vehicles, runs off-road, or a crash occurs further in the platoon of cars due to the unexpected change of the traffic flow.

The safety impact of litter is not limited to motor vehicles and can also affect bicycle and scooter riders. Micromobility is a growing movement in the U.S. Several ride-sharing companies have emerged in the last few years and personal or shared use of bicycles, e-bikes, electric scooters, and other devices has significantly increased. Transportation agencies are also trying to move towards the Complete Street approach and incorporate safe means of transportation for all road users. Litter can impact this group in several ways. Broken glasses and other smaller size solid litter usually end up at the edges of the streets which are the main portion of the road used for micromobility. Further, larger objects are also either dumped on the side of the road or eventually end up there. This can indirectly put riders in danger by forcing them to shift their path towards the center of the road in order to avoid the objects, and consequently increasing the risk of a collision. Bicyclists and scooter riders are considered vulnerable road users who are at a higher risk of severe injuries and fatality if being involved in a crash. Therefore, providing them with a safe and secure transportation platform can significantly encourage more people to use these devices. 
Another safety concern with litter and cigarette butts, in particular, is the risk of fire. Although it is not very common, a discarded lit cigarette butt can potentially put another vehicle on fire. In a very tragic incident in the Mont Blanc Tunnel between France and Italy, in 1999, a cigarette butt caused a fire which led to 39 deaths, $\$ 1$ million economic loss, and the tunnel being shut down for 3 years. In further investigations, it was revealed that the discarded cigarette was sucked into another vehicle's air intake system and put the air filter on fire (Leistikow, Martin, \& Milano, 2000). Figure 16 shows an image of the massive damage caused by this tragedy.

\section{Litter Abatement Strategies}

Current efforts for reducing roadside litter can be classified into preventive or removal methods.

\subsection{Litter Removal}

The litter removal programs are mainly done through the state DOTs as a combination of paid crews, volunteer works, and inmate and public service programs. Nelson (2001) collected the information from 28 states in the U.S. and identified the share of each group which is shown in Figure 17. This figure indicates that the DOT maintenance crews account for the majority of the roadside litter collections. Special service crews include paid youth corps, those serving public service sentences, and disadvantaged worker and work rehabilitation programs. These programs are typically supervised and paid by minimum wage to lower the cost of litter removal compared to a paid maintenance crew or contractors while providing an opportunity for those who need to earn an extra wage. Youth corps is usually a summer program for teenagers. Utilizing youth offenders, community service, and inmate work programs is a more common strategy that runs in many states for non-violent offenders.

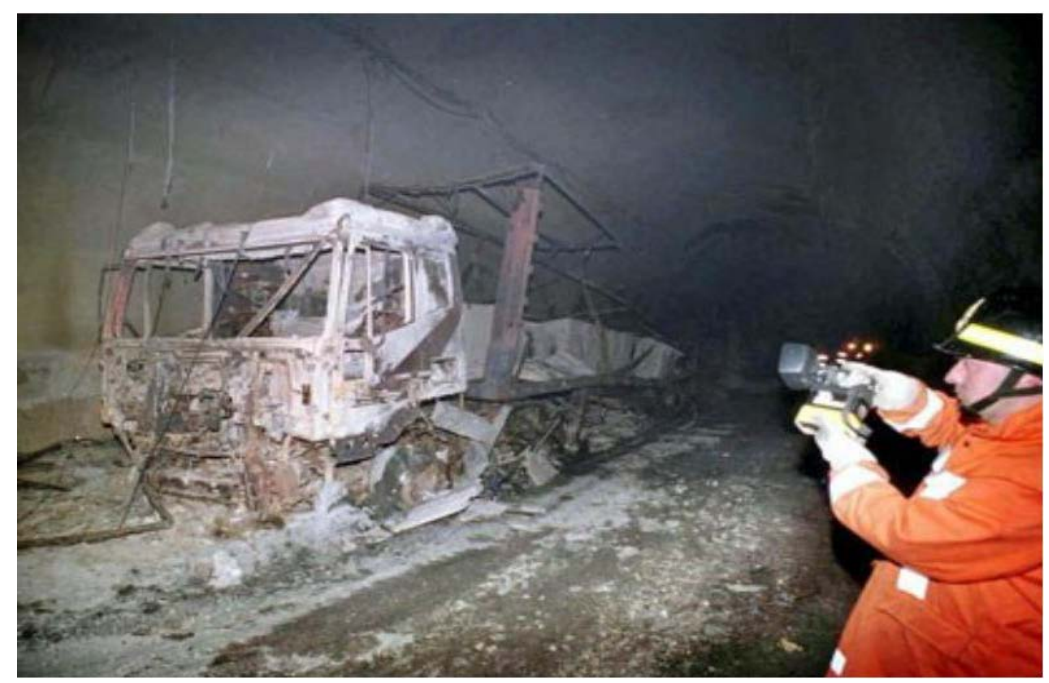

Figure 16. A scene after the 1999 fire in Mont Blanc tunnel (Wallis, 2021). 


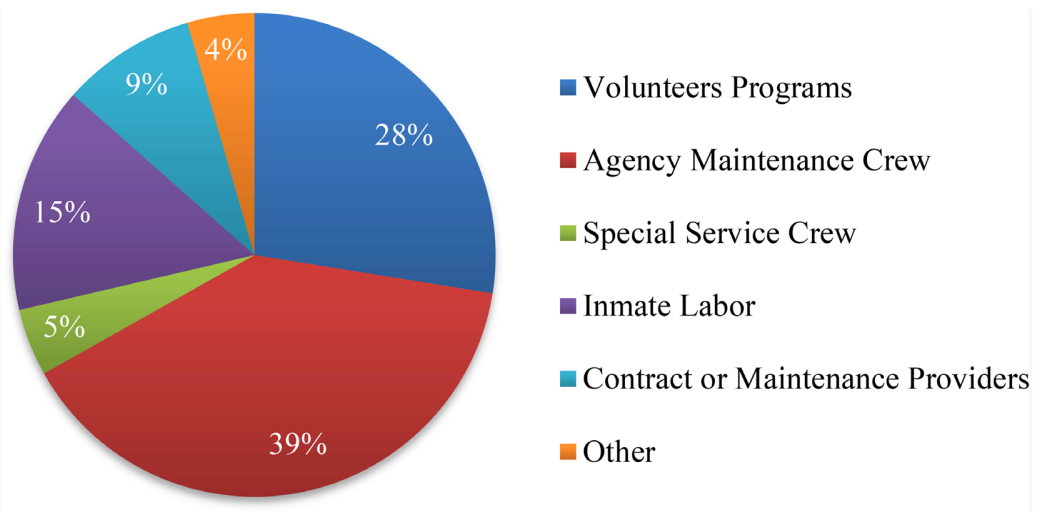

Figure 17. The average share of different groups in litter pick-up in twenty-eight states (Nelson, 2001).

The role of maintenance crews and maintenance contractors varies significantly from state to state. In most volunteer programs, volunteers are not allowed to work in hazardous locations and medians due to safety reasons, therefore state maintenance crews and contractors focus on the cleanup of hazardous materials and cleanup in hazardous locations (Nelson, 2001).

\section{Volunteer Programs}

Many non-profit organizations have devoted their efforts to litter pick-up and volunteer works have become an important part of the litter removal programs. KAB national study (2008) estimated that volunteer cleanup programs save taxpayers an average of $\$ 677$ million. As shown in Figure 17 volunteer programs account for nearly a third of the roadside litter pick-up efforts. In some states such as Washington and West Virginia, the share of volunteer programs can be even over $80 \%$ (Nelson, 2001). Two of the most well-known programs in the U.S. are Adopt-A-Highway (AAH) and Sponsor-A-Highway. AAH originated in Texas in 1985 and since then has spread all over the country and since then it has cleaned over 1 million miles of U.S. highways and interstates (Adopt-A-Highway, 2020). In $2008 \mathrm{AAH}$ had over 1.1 million individuals and groups as volunteers (Stein, 2009). The adoption approach doesn't limit to highways and there are similar programs for roads, streets, parks, beaches, and hiking trails.

In most AAH programs volunteers will be in charge of cleaning a designated one to three-miles section of the road two to four times per year and in exchange, a sign will be placed in that section to recognize the volunteer group. For urban streets, the frequency of clean-up can be higher. Program funding typically comes from maintenance budgets, a state's general fund, litter taxes, or environmental grant programs (Nelson, 2001). Most corresponding agencies will provide safety instruction and operation supplies such as gloves, vests, and trash bags for volunteers. Sponsor-A-Highway follows a very similar concept to the AAH, except, the sponsor covers the cost and the maintenance provider for litter and debris removal will clean up a specific section of the highway (Nelson, 2001). In return, the state will place a billboard on that section of the road with the name and logo 
of the sponsor which can serve as a free advertisement and tends to encourage more businesses and companies to participate in this program.

Despite the great benefits of volunteer programs, some challenges are involved as well. The safety and health of volunteers are major concerns. There is always a risk of collisions for both volunteers and other motorists on the road during the clean-up process. Further, roadside litter can consist of all sorts of materials and volunteers may get guts and infections while handling sharp objects, medical waste, animals or insects, drug-related items, human urine, and virus-infected items (masks and gloves especially due to COVID-19). A different type of challenge for DOTs appeared when some controversial groups such as Klu-Klux-Klan, neo-Nazi groups, and nudists tried to participate in the program and have their name and logo on the billboards (Allen, 2011).

\subsection{Prevention}

Three major approaches to litter prevention are education and public awareness, receptacles' design, and consequence control (Bitgood, Carnes, \& Thompson, 1988).

\subsubsection{Education and Public Awareness}

Education programs to establish anti-litter behaviors are most effective when starting from an early age (Nelson, 2001). Environmental educational materials should be included in the school programs to teach children the proper disposal of trash and recycling principles as well as the environmental consequences of littering. Although might be more challenging, education can still be effective for older age groups as well. Billboard advertising and paid advertising time on television and the radio are the most commonly used means for reaching a large audience. Forbes (2009) claims that paid advertising programs targeting the age groups identified as primarily responsible for causing litter are the most costeffective approaches. It was claimed that they prevent littering at the cost of $\$ 0.02$ per item and can lead to $70 \%$ reductions in litter in 6 years, but the advertising program needs to be adequately supported and sustained to achieve good results (Forbes, 2009). Some other studies have also shown that research-based advertising if funded and continued for a minimum of five years can be effective in reducing litter in a larger scale (Morris, 2006). Don't Mess with Texas is a successful example of this kind. The campaign reported in 2013 that $98 \%$ of Texas residents are familiar with the slogan, and they had reduced the visible litter by 34\% since 2009 (Zero Waste Scotland, 2017).

Roadside advertising should boost a sense of social responsibility, educate the public about the fines and consequences of littering, and encourage witnesses to report the litterers. Forbes (2009) suggests increasing the effectiveness of roadside advertising the message is better to appear in a series and include a method for reporting the litterers (such as a phone number or a phone app). Schultz (2009) claims that using pictures of littered areas and messages 
that emphasize on the high rate of existing litter can even have a reverse impact because of implying the message that "littering is common". This study suggests focusing on the fact that littering is wrong and condemned by the majority.

In addition to the conventional means of advertisement such as roadside billboards, and radio, TV social media, and internet websites should be considered as a great way to reach a large audience, particularly, the younger generation who happens to be at the highest risk of littering. While a billboard advertisement can be seen only by hundreds of drivers, a message on social media can easily be seen by millions especially if endorsed by celebrities.

\subsubsection{Receptacle Design}

Finnie (1973) conducted experiments involved placing litter receptacles along highways and city streets in three cities in the U.S. The Richmond and St. Louis experiments indicate reductions of $16.7 \%$ and $14.7 \%$ in urban areas and $28.6 \%$ along highways. The Philadelphia experiment indicates that litter cans reduce litter by $56 \%$ in a clean area and $35 \%$ in a dirty area. A more recent effort evaluated the effectiveness of receptacles in reducing litter and found that receptacles average a $40 \%$ reduction in litter in both urban and rural settings (Forbes, 2009). Schultz (2009) observed that the average distance of litterers from a receptacle was 29 feet, and believes that the availability of receptacle's can strongly affect the amount of litter.

As it was discussed earlier, cigarette butts are the most common litter item on the roads, and vehicle occupants are a major source. A significant difference in litter behavior between discarding cigarette butts and other types of litter has been reported (Schultz, 2009). This difference can potentially due to the fact that one can hold on to a fast-food packaging or a piece of paper, but holding to a lit cigarette but can be much more challenging. Schultz's observations indicated that the availability of ash receptacles is significantly less that regular trash cans and doesn't meet the need of smokers. Especially because of the recent policies that bans indoor smoking, more ash receptacles should be provided for smokers in outdoor areas. Anti-litter messages always ask people not to flick their cigarettes out of their vehicles but they rarely offer any alternatives. Smoker drivers might be willing to stop tossing their cigarette butts out of their vehicle if they have a convenient alternative for disposing of it safely in their car. Encouraging drivers to use small trash cans and ashtrays in their cars can be a cheap solution to reducing cigarette litter on the roads.

Ballot Bins is a campaign that was launched in Edinburg and London targeting the general waste and cigarette butts. The beans gave people the option to vote with their litter by asking engaging questions, like choosing between two rival soccer teams, automotive brands, and such (Figure 18). This campaign received a great deal of exposure where nearly $90 \%$ of the businesses and people in the area were aware of it. In London, the campaign focused on one busy street. 


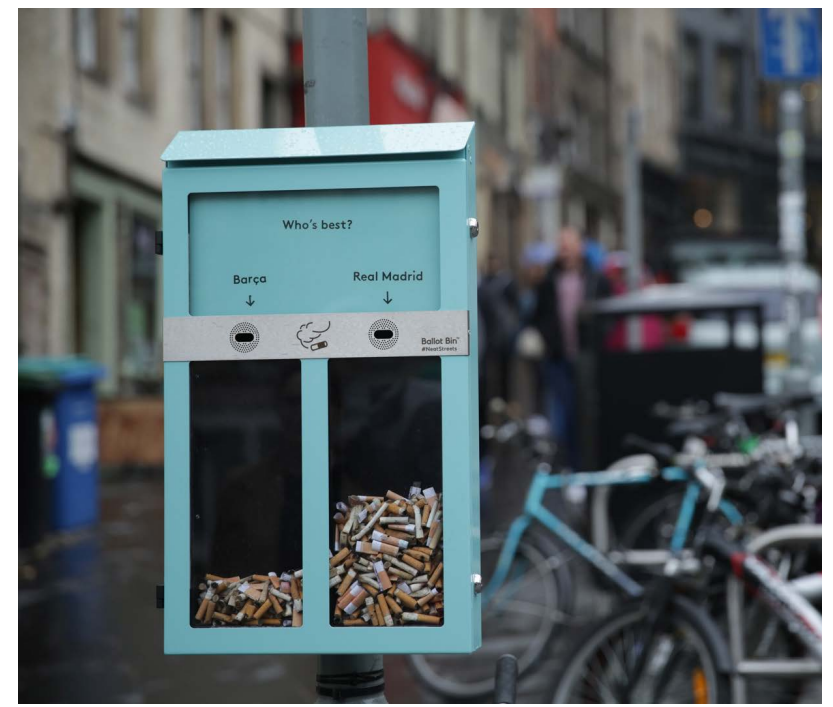

Figure 18. An example of a ballot bin (Ballot Bin, 2021).

Voting-by-bin went viral on social media and the campaign buzz drew 80 inquiries asking to use ballot bins in other areas (Zero Waste Scotland, 2017). The ballot bins cost around $\$ 300$ and they were proven to reduce cigarette butt littering by $46 \%$ (Ballot Bin, 2021).

The receptacle should be covered and have the right capacity. Similar to the dumpster shown earlier in Figure 9, many trash cans and dumpsters get full sooner than their collection date comes and litter would overflow on their surroundings. Receptacles should also be properly covered to prevent their content from being blown by the wind and scattered around.

\subsubsection{Consequence Control}

Consequence control through an enforcement program is an essential tool for litter prevention strategies and can be one of the most effective ones. A successful enforcement program needs to be comprehensive and applicable. Effective legislation, law-enforcement training, and public awareness of the law are some major components of an effective enforcement effort (Nelson, 2001). The consequence control approach in the U.S. can vary from one state to another in terms of the definition of terms, fines, and strictness of the enforcement. Internationally, some countries such as Singapore and Japan are well-known for their severe anti-littering laws and penalties. Littering and illegal dumping can lead to fines and jail sentences in most states of the U.S. However, catching the offenders while committing the crime can be challenging. Most successful cases of enforcement are usually illegal dumping since the act of dumping usually takes longer than littering and there is a higher chance for an officer to catch the offender. Moreover, littering can sometimes be justified as accidental or intentional, dumping is firmly considered as a deliberate act (Nelson, 2001). With the advances in new technologies, catching litterers is becoming more feasible. Using Closed-Circuit Television Cameras (CCTV) can be an effective method especially for illegal dumping hot spots (Forbes, 
2009). Some developing technologies such as (intuVision, 2021) can even use CCTV recordings to automatically detect any significantly large item that is thrown out of a moving vehicle, identify the vehicle's license plate, and report the case.

In summary, current efforts for reducing roadside litter were classified into preventive or removal methods. The litter removal programs are mainly done through the state DOTs as a combination of paid crews, volunteer works, and inmate and public service programs. Litter prevention, on the other hand, are education and public awareness, receptacles' design, and consequence control, each of which were described above.

\section{Conclusion}

Litter is associated with many social, environmental, and economical issues. It can also be a source of safety hazards for road users. The issue of litter is a complex matter caused by various reasons which do not have a single solution. Removal methods focus on collecting the existing litter which can be very effective on a short-term basis but they are usually costly. Furthermore, roadside litter is a growing problem due to the increase in VMT and contributing factors such as the emergence of the COVID-19 pandemic. Therefore, people are littering much faster than DOTs and volunteer programs can pick it up. Preventive methods, on the other hand, following a longer-term approach that might even take up to a generation to be completely effective. A long-term effort for mitigating this problem must include all the discussed methods to gain maximum success. To change the littering behaviors, engaging communities, continuous educational programs, encouraging volunteer works, improving the design of the trash receptacles, revising legislation, and establishing more effective enforcement methods are the major effective strategies. In terms of public awareness, it is also very important to choose the proper methods to maximize the audience and send the right message to the right group. Social media, especially if it is accompanied by celebrities' endorsement is expected to be a strong tool.

Although a change in littering attitude is fundamental for any litter abatement program, the role of producers should not be ignored either. The drastic surge in the amount of plastic litter in the last 50 years is a direct result of the increase of the products, and producers' choice of packaging material. Governments need to encourage, or even enforce industries to think and act with a more sustainable approach. Using recyclable material, and reducing the number of wrappers and other packaging items can make a big difference in reducing the number of roadside litter. Furthermore, the distribution of some products such as free magazines and advertising fliers should be strictly regulated since these products are known as “instant litter".

\section{Acknowledgments}

The authors would like to express their gratitude to the Delaware Department of 
Transportation and the Delaware Center for Transportation for supporting this project. In particular, all the assistance received from Mr. Scott Neidert who served as the project manager is much appreciated. Furthermore, we would like to thank the Keep Delaware Beautiful organization and Sarah Culler, in particular, for sharing their survey data.

\section{Conflicts of Interest}

The authors declare no conflicts of interest regarding the publication of this paper.

\section{References}

Adopt-A-Highway (2020, June 16). About Us-Adopt a Highway Litter Removal Service of America. https://adoptahighway.net/about-us

Allen, S. (2011). Own the Road: A Brief History of the Adopt-a-Highway Program. https://www.mentalfloss.com/article/27018/own-road-brief-history-adopt-highway-pr ogram

Ballot Bin (2021, January 10). Keep Streets Butt-Free with the Ballot Bin. Ballot Bin. https://ballotbin.co.uk

Bareket, Z., Blower, D. F., \& MacAdam, C. (2000, August 31). Blowout Resistant Tire Study for Commercial Highway Vehicles. UMTRI-2000-28.

https://deepblue.lib.umich.edu/bitstream/handle/2027.42/1309/94093.0001.001.pdf?seq uence $=2$

Beck, R. W. (2007a, January). Georgia 2006 Visible Liter Survey: A Baseline Survey of Roadside Litter. Keep America Beautiful and Georgia Department of Community Affairs. http://cummingutilities.com/2006 Georgia Litter Report Final .pdf

Beck, R. W. (2007b). A Review of Litter Studies, Attitude Surveys and Other Litter-Related Literature.

Bitgood, S., Carnes, J., \& Thompson, D. (1988). Control of Littering: A Comparison of Three Approaches. Visitor Behavior, 2, 7-8.

https://www.informalscience.org/sites/default/files/VSA-a0a2j5-a 5730.pdf

Burns \& McDonnell Engineering Company, Inc. (2020, January). Pennsylvania Litter Research Study.

https://files.dep.state.pa.us/waste/Bureau\%20of\%20Waste\%20Management/WasteMgtPorta 1Files/Littering/Pennsylvania\%20Litter\%20Research\%20Study\%20Final\%20Report\%201.30. 2020.pdf

Burns, J. C. (1981). Roughness and Roadway Safety (pp. 8-14). Transportation Research Record 836. http://onlinepubs.trb.org/Onlinepubs/trr/1981/836/836-002.pdf

Conroy-Ben, O., \& Christensen, T. (June 2013). Reducing Highway Litter. Utah Department of Transportation. https://rosap.ntl.bts.gov/view/dot/26223

DSM Environmental, \& MSW Consultants (2018). State of Delaware Baseline Statewide Visual Litter Study.

Environmental Protection Agency (1998). EPA Illegal Dumping Prevention Guidebook (EPA 905-B-97-001).

Environmental Resources Planning (2015, January 16). 2015 Anacostia Watershed Litter Survey: A Survey of Litter along 96 Roadway and Non-Roadway Sites within the Anacostia Watershed. Conducted in District of Columbia, Montgomery County, and Prince 
George's County.

Finnie, W. C. (1973). Field Experiments in Litter Control. Environment and Behavior, 5, 123-144. https://doi.org/10.1177/001391657300500201

Forbes, G. J. (2009). Reducing Litter on Roadsides. In National Academies of Sciences, Engineering, and Medicine (Vol. 394). The National Academies Press. https://www.nap.edu/cover/14250/450

Forbes, G. J. (2004). The Safety Impact of Vehicle-Related Road Debris. AAA Foundation for Traffic Safety.

GAO (2012, November). Highway Safety: Federal and State Efforts Related to Accidents That Involve Non-Commercial Vehicles Carrying Unsecured Loads. Report to Congressional Committees. https://www.gao.gov/products/gao-13-24

Gershman, Brickner \& Bratton, Inc. (2005). @2004 New Jersey Litter.

Gregory, M. R. (2009). Environmental Implications of Plastic Debris in Marine SettingsEntanglement, Ingestion, Smothering, Hangers-On, Hitch-Hiking and Alien Invasions. Philosophical Transactions of the Royal Society B, Biological Sciences, 364, 2013-2025. https://doi.org/10.1098/rstb.2008.0265

IntuVision (2021, May 3). Intuitive Video Analytics. https://www.intuvisiontech.com

Kelling, G. L., \& Coles, C. M. (1997). Fixing Broken Windows: Restoring Order and Reducing Crime in Our Communities. A Touchstone Book, Simon \& Schuster.

Leistikow, B. N., Martin, D. C., \& Milano, C. E. (2000). Fire Injuries, Disasters, and Costs from Cigarettes and Cigarette Lights: A Global Overview. Preventive Medicine, 31, 91-99. https://doi.org/10.1006/pmed.2000.0680

Morris, E. L. (2006). Effective Litter Reduction. Kutztown University of Pennsylvania.

Nelson, D. C. (2001). Roadside Litter Control: A Survey of Programs and Practice. Maryland State Highway Administration.

http://www.roads.maryland.gov/opr research/md-01-sp707b4i-roadside-litter-control a-survey-of-programs-and-practice-report.pdf

Novotny, T. E., Lum, K., Smith, E., Wang, V., \& Barnes, R. (2009). Cigarettes Butts and the Case for an Environmental Policy on Hazardous Cigarette Waste. International Journal of Environmental Research and Public Health, 6, 1691-1705. https://doi.org/10.3390/ijerph6051691

Pacific, N. (2019, April 25). Plastic in Everyday Life-Let's Reduce the Use! Natura Pacific. https://www.natura-pacific.com/plastic-everyday-life-lets-reduce-use

Silva, A. L. P., Prata, J. C., Walker, T. R., Duarte, A. C., Ouyang, W., Barcelò, D., \& Rocha-Santos, T. (2021). Increased Plastic Pollution Due to COVID-19 Pandemic: Challenges and Recommendations. Chemical Engineering Journal, 405, Article ID: 126683. https://doi.org/10.1016/j.cej.2020.126683

Prata, J. C., Silva, A. L. P., Walker, T. R., Duarte, A. C., \& Rocha-Santos, T. (2020). Covid-19 Pandemic Repercussions on the Use and Management of Plastics. Environmental Science \& Technology, 54, 7760-7765. https://doi.org/10.1021/acs.est.0c02178

Rath, J. M., Rubenstein, R. A., Curry, L. E., Shank, S. E., \& Cartwright, J. C. (2012). Cigarette Litter: Smokers' Attitudes and Behaviors. International Journal of Environmental Research and Public Health, 9, 2189-2203. https://doi.org/10.3390/ijerph9062189

Responsive Management (2006). Georgia Residents' Opinion on Litter and Anti-Littering Programs in Georgia. Georgia Governor's Office and the State of Georgia's Litter Abatement and Prevention Initiative. 
https://journals.sagepub.com/doi/pdf/10.1177/001391657300500201?casa token=F-B I H6jUi0AAAAA:k wypsB5GOFJZ310JCX0vdFo9OOXE9lbfZtGozb6oTk7-Hkv1WLnd L80p5pzuUT-Tfh137Nzy-Sf

Ritchie, H., \& Roser, M. (2018). Plastic Pollution.

https://ourworldindata.org/plastic-pollution

Schultz, W. (2009). Littering Behavior in America Results of a National Study. Keep America Beautiful, Inc.

https://kab.org/wp-content/uploads/2019/10/NewsInfo_Research LitteringBehaviorin America 2009Report Final.pdf

Semuels, A. (2021, March 26). "Garbage Freaking Everywhere" as Americans Venture Outdoors after a Year of Lockdowns. Time. https://time.com/5949983/trash-pandemic/

Slaughter, E., Gersberg, R. M., Watanabe, K., Rudolph, J., Stransky, C., \& Novotny, T. E. (2011). Toxicity of Cigarette Butts, and Their Chemical Components, to Marine and Freshwater Fish. Tobacco Control, 20, i25-i29. https://doi.org/10.1136/tc.2010.040170

Spacek, S. L. (2008, March 9). The (First) American State Litter Scorecard (2008): A Sociopolitical Inquiry into Littering and the Response Role of 50 American States. Texas State University.

https://www.slideshare.net/stevewonder2/the-american-state-litter-scorecard-presentat ion

Spink, S. J. S. (2006). Serious Motorcycle Crashes in Michigan.

State of Delaware News (2019). Governor Carney Announces Expansion of DelDOT's Work-a-Day Earn-a-Pay Program. State of Delaware News.

https://news.delaware.gov/2019/07/18/governor-carney-announces-expansion-of-deldo ts-work-a-day-earn-a-pay-program

Stein, S. R. (2018). New Jersey 2018 Litter Survey. https://njclean.org/images/VLS/2018-NJ-Litter-Survey-Final-Report-July-24.pdf

Stein, S. R. (2009). 2008 National Visible Litter Survey and Litter Cost Research Study (No. 20878).

Stein, S. R., \& Environmental Resources Planning (2010). Northeast 2010 Litter Survey.

Thiele, C. J., Hudson, M. D., Russell, A. E., Saluveer, M., \& Sidaoui-Haddad, G. (2021). Microplastics in Fish and Fishmeal: An Emerging Environmental Challenge? Scientific Reports, 11, Article No. 2045. https://doi.org/10.1038/s41598-021-81499-8

Wallis, S. (2021, January 15). Fire Damage Rebuild of Mont Blanc Road Link. https://www.tunneltalk.com/Fire-safety-Jun01-Mont-Blanc-highway-fire-reconstructio n.php

Zero Waste Scotland (2017). 7 of the Best Litter Prevention Campaigns from around the World. https://www.zerowastescotland.org.uk/litter-flytipping/top-campaigns 